\title{
Development of novel EST-SSR markers derived from Japanese pear (Pyrus pyrifolia)
}

\author{
Chikako Nishitani, Shingo Terakami, Yutaka Sawamura, Norio Takada and Toshiya Yamamoto*
}

National Institute of Fruit Tree Science, 2-1 Fujimoto, Tsukuba, Ibaraki 305-8605, Japan

\begin{abstract}
We developed 73 novel expressed sequence tag (EST) - simple sequence repeat (SSR) markers based on ESTs derived from 11 different cDNA libraries of the Japanese pear (Pyrus pyrifolia Nakai) cultivar 'Housui', comprising 30, 36, two, one, and four SSRs with repeat motifs of di-, tri-, tetra-, penta-, and hexanucleotides, respectively. Forty-eight EST sequences showed significant homology to Arabidopsis thaliana genes. The linkage groups and positions of 57 loci generated from 53 SSR markers covering all 17 linkage groups, were identified. These EST-SSRs will be useful for high-throughput genotyping of marker-assisted selection. The numbers of alleles and the observed and expected heterozygosities at single-locus EST-SSR markers in ten Japanese and ten European pears suggest high polymorphism and heterozygosity of the ESTSSRs. Di-nucleotide EST-SSRs showed two to three times the polymorphism and heterozygosity of trinucleotide EST-SSRs. Some of the EST-SSRs proved transferable to other species in the Rosaceae, paving the way for the development of markers for the same phenotypic traits among species of the Rosaceae.
\end{abstract}

Key Words: expressed sequence tag, genome mapping, Japanese pear, simple sequence repeat.

\section{Introduction}

Pears (Pyrus spp.), which belong to the subfamily Maloideae in the family Rosaceae, are one of the most important fruits grown in Europe and Asia for the past 2000 to 3000 years. Pears are grown commercially in all the temperate regions in more than 50 countries (Bell 1990, Bell et al. 1996). The Japanese pear (Pyrus pyrifolia Nakai), the European pear (P. communis L.), and Chinese pears (P. bretschneideri Rehd. and $P$. ussuriensis Maxim.) are the major species grown commercially. The Japanese pear is grown in East Asia, and the European pear in Europe, North America, and temperate regions of the southern hemisphere (Bell 1990).

Molecular markers combined with high-density genetic linkage maps are useful for fundamental and applied genetic researches and for breeding programs. Simple sequence repeat (SSR) markers provide a reliable method for constructing genetic maps and evaluating genetic diversity because of their co-dominant inheritance and the abundance of alleles per locus (Weber and May 1989). More than 100 SSR markers have been developed from genomic sequences of Japanese and European pears (Yamamoto et al. 2002a, 2002b, 2002c, Sawamura et al. 2004, Fernandez-Fernandez et al. 2006, Inoue et al. 2007). SSR markers developed in pear were used as anchor loci for reference genetic linkage maps of pear (Yamamoto et al. 2007). Additionally, SSR markers developed in of apple (Malus $\times$ domestica Borkh.; also

Communicated by M. Hirai

Received May 19, 2009. Accepted September 7, 2009.

*Corresponding author (e-mail: toshiya@affrc.go.jp)
Maloideae) have been successfully applied to pears (Guilford et al. 1997, Gianfranceschi et al. 1998, Liebhard et al. 2002, Silfverberg-Dilworth et al. 2006). Transferability of SSR markers within the Maloideae was investigated (Yamamoto et al. 2001, Liebhard et al. 2002). Apple SSR markers were used for constructing genetic linkage maps in pears and colinearity between pear and apple was identified (Dondini et al. 2004, Pierantoni et al. 2004, Yamamoto et al. 2007). However, not enough SSR markers have been developed to allow marker-assisted breeding in pear, and very few functional genes have been used as selection markers.

Several sequencing projects have generated more than 250,000 expressed sequence tags (ESTs) in apple over the past few years (Newcomb et al. 2006, Naik et al. 2006). SSRs associated with these sequences constitute a large resource of markers which have remained largely unexploited. Furthermore, since EST-based SSRs are located around conserved coding regions, they are often more transferable between species (Decroocq et al. 2003) than genomic SSRs. The Genome Database for Rosaceae (GDR, http://www. bioinfo.wsu.edu/gdr/, 5 May, 2009) lists 359,001 EST sequences, including 250,907 in Malus, 83,751 in Prunus, 18,729 in Fragaria, and 5,284 in Rosa, but only 330 EST sequences and 271 unigenes of Pyrus. Therefore, it is necessary to obtain many more EST sequences in pears to provide a source of functional markers such as SSRs and single nucleotide polymorphisms (SNPs). EST-derived markers developed for candidate genes may be suitable for relatively highthroughput genotyping for marker-assisted selection (MAS) (Celton et al. 2009).

Here, we developed EST-SSR markers from more than 
1,000 EST sequences with motifs of di-, tri-, tetra-, penta-, and hexa-nucleotide repeats, which were collected from 11 cDNA libraries of the Japanese pear cultivar 'Housui' (syn. 'Hosui'). We established 73 EST-SSR markers, characterized their polymorphism, heterozygosity, and map position, and examined their transferability in apple and Prunus.

\section{Materials and Methods}

\section{Plant materials and DNA isolation}

For construction of cDNA libraries we used the Japanese pear (Pyrus pyrifolia Nakai) cultivar 'Housui' (syn. 'Hosui'). For evaluation of EST-SSR markers we used ten Japanese pear cultivars: 'Atago', 'Choju', 'Chojuro', 'Housui', 'Ishiiwase', 'Kinchaku', 'Nanseichabo', 'Niitaka', 'Nijisseiki', and 'Okusankichi'. To examine cross species amplification of the EST-SSR markers we used ten European pear (Pyrus communis L.) cultivars: 'Bartlett', 'Brandy Wine', 'Conference', 'Flemish Beauty', 'Margeritt Marilla', 'La France', 'Passe Crassane', 'Perrie Corneir', 'Precose', and 'Winter Nelis'. To test transferability across genera we used apple (Malus $\times$ domestica Borkh.) cultivars 'Fuji' and 'Sansa', almond (Prunus dulcis Mill.) cultivar 'Texas', and peach (Prunus persica (L) Batsch.) cultivar 'Earlygold'. 'Texas' and 'Earlygold' were previously used for the Prunus reference genetic linkage map (Dirlewanger et al. 2004, Howad et al. 2005).

Plant samples were maintained at the National Institute of Fruit Tree Science (NIFTS) (Tsukuba and Morioka, Japan). Young leaves were collected and stored at $-80^{\circ} \mathrm{C}$ for DNA extraction. Genomic DNAs were isolated from leaves with G2 Buffer and Genomic-tip 20/G anion-exchange tips (Qiagen, Germany) (Yamamoto et al. 2006). Genomic DNAs of 'Texas' and 'Earlygold' were kindly provided by Dr. P. Arús (CSIC-IRTA, Spain).

\section{Construction of cDNA libraries and EST analysis}

We constructed 11 cDNA libraries of 'Housui': two from leaves (buds and fully expanded), three from flowers (buds, balloon stage, and open), and six from fruit tissues: at 2-3, 6-7, 11-12, 15-16, 20-21 (mature fruits), and 23-24 (overmature fruits) week after full bloom (Nishitani et al. 2009). Total RNA was extracted by the Hot-Borate method (Wan and Wilkins 1994). Poly(A)+ RNA was purified with a FastTrack 2.0 kit (Invitrogen, USA). The cDNA libraries were constructed with a ZAP-cDNA Gigapack III Gold Cloning kit (Stratagene, USA) or a Creator SMART cDNA Library Construction kit (Clontech, USA). Colonies were manually picked, and plasmids were purified and sequenced with a BigDye Terminator v. 3.1 Cycle Sequencing kit (Applied Biosystems, USA) according to the manufacturer's instructions. Unincorporated nucleotides were removed by column chromatography on a Sepharose G50 column (Amersham Pharmacia, UK) from Multiscreen 96-well plates (Millipore, USA) before sequencing with an ABI Prism 3130xl sequencer (Applied Biosystems, USA). EST se- quences were processed to remove the vector and unreliable sequences (quality value $<20$ ) by using the Pregap4 software (Bonfield et al. 1995), and sequences longer than $200 \mathrm{bp}$ were processed for contig assembly with the Gap4 software (Bonfield et al. 1995).

From 28,704 cDNA clones sequenced by single-pass sequencing from the $5^{\prime}$ end we obtained 23,755 sequences longer than $200 \mathrm{bp}$. After the removal of redundant clones (Nishitani et al. 2009), contig assembly of raw sequences produced 10,350 unigenes (non-redundant sequences). Functional categorization of the non-redundant sequences was based on the GoSlim gene ontology (Berardini et al. 2004) of their homologs in Arabidopsis. Homology search for Arabidopsis genes was performed by BLASTX.

\section{EST-SSR development}

SSR sequences among the 10,350 unigenes were searched by using the Tandem Repeats Finder software (Benson 1999) with alignment parameters set to match $=2$, mismatch $=7$, and indel $=7$. We found 1,097 ESTs with repeat sequences, comprising 507 di-nucleotide, 369 trinucleotide (or hexa-nucleotide), 72 tetra-nucleotide, and 149 penta-nucleotide motifs. We considered 12 or more repeat nucleotides as criteria of SSRs; viz., six di-nucleotides, four tri-nucleotides, three tetra-nucleotides, three pentanucleotides, and two hexa-nucleotides.

Primer pairs were designed with the Primer3 Web interface (Rozen and Skaletsky 2000, http://frodo.wi.mit.edu/ primer3/input.htm). General primer picking conditions used a primer size of 20-25 bp (optimum $23 \mathrm{bp}$ ), a primer $\mathrm{Tm}$ of 57-67 ${ }^{\circ} \mathrm{C}$ (optimum $63^{\circ} \mathrm{C}$ ), a maximum $\mathrm{Tm}$ difference of $1^{\circ} \mathrm{C}$, a primer GC content of 50-60\% (optimum 55\%), and a product size range of 100-300 bp.

\section{SSR analysis}

SSR amplification was performed in a $10-\mu 1$ reaction mixture containing $10 \mathrm{mM}$ Tris $\cdot \mathrm{HCl}(\mathrm{pH} 8.3), 50 \mathrm{mM} \mathrm{KCl}$, $1.5 \mathrm{mM} \mathrm{MgCl}_{2}, 0.001 \%$ gelatin, $0.2 \mathrm{mM}$ each dNTP, $5 \mathrm{pmol}$ each forward primer (fluorescently labeled with Fam/Vic/ $\mathrm{Ned}$ ) and reverse primer (unlabelled), $5 \mathrm{ng}$ genomic DNA, and 0.5 units Taq polymerase (Invitrogen, USA). DNA was amplified in 35 cycles of $94^{\circ} \mathrm{C}$ for $1 \mathrm{~min}, 55^{\circ} \mathrm{C}$ for $1 \mathrm{~min}$, and $72^{\circ} \mathrm{C}$ for $2 \mathrm{~min}$. When clear amplification was not obtained at $55^{\circ} \mathrm{C}$ annealing temperature, we tried 50 and $60^{\circ} \mathrm{C}$. The PCR products were separated and detected in a PRISM 3100 DNA sequencer (Applied Biosystems, USA). The size of the amplified bands was determined against an internal standard DNA (400HD-Rox, Applied Biosystems, USA) by the GeneScan software (Applied Biosystems, USA).

\section{Mapping of SSR markers}

Two populations were used for genome mapping of the EST-SSRs: $63 \mathrm{~F}_{1}$ individuals from an interspecific cross between European pear 'Bartlett' and Japanese pear 'Housui', and $55 \mathrm{~F}_{1} \mathrm{~s}$ from an interspecific cross between Japanese pear 'Shinsei' and 282-12 ('Housui' $\times$ European pear 'La 
France') (Yamamoto et al. 2004, 2007, Terakami et al. 2009). Genetic linkage maps of 'Bartlett' and 'Housui' were constructed by adapting the double pseudo-testcross strategy (Grattapaglia and Sederoff 1994) because of the selfincompatibility of pear (Kikuchi 1929). A genetic linkage map of 'La France' was constructed by a $\mathrm{BC}_{1}$ strategy by scoring La France alleles in 282-12.

Pear genomic SSRs (Fernandez-Fernandez et al. 2006, Inoue et al. 2007) and apple SSRs (Silfverberg-Dilworth et al. 2006) were tried and newly mapped in addition to the previous reports (Yamamoto et al. 2007, Terakami et al. 2009). We used the three genetic linkage maps of 'Bartlett', 'Housui', and 'La France' for identification of linkage groups (LGs) and positions of EST-SSRs. JoinMap v. 3.0 (Van Ooijen and Voorrips 2001) was used to construct the genetic linkage maps, and the Kosambi's mapping function was used to convert recombination units into genetic distances. The mapping analysis used a minimum LOD score of 5.0.

\section{Data analysis}

Using the CERVUS v. 2.0 software (Marshall et al. 1998), we estimated the observed heterozygosity $\left(H_{O}\right)$ and expected heterozygosity $\left(H_{E}\right)$ at single-locus EST-SSR markers in the ten Japanese and ten European pears. $H_{O}$ was calculated as the ratio of the heterozygous genotypes scored at each locus. $H_{E}$ was calculated using an unbiased formula from allele frequencies as $1-\Sigma \mathrm{pi}^{2}(1 \leq \mathrm{i} \leq \mathrm{m})$, where $\mathrm{m}$ is the number of alleles at the target locus and pi is the allele frequency of the $i^{\text {th }}$ allele at the target locus.

\section{Results}

\section{Development of EST-SSR markers}

Out of 98 EST sequences tested, 73 were successfully established as SSR markers; these amplified fragments from 'Housui' with the target size, and gave clear and stable amplification in all pear cultivars. The EST-SSR markers comprised 30 di-nucleotide, 36 tri-nucleotide, two tetranucleotide, one penta-nucleotide, and four hexa-nucleotide motifs (Table 1). The remaining 25 sequences generated no or unstable amplification, or large bands possibly due to the existence of introns, and were excluded from further analysis.

\section{Characteristics of EST-SSR markers}

Forty-eight EST-SSR sequences showed significant homology to Arabidopsis thaliana genes (Table 2). Marker TsuENH001 showed high homology to a ferredoxinNADP(+) reductase gene of $A$. thaliana, and TsuENH091 was identified as a putative serine/threonine protein kinase gene. Putative gene functions were identified for more than $60 \%$ of the sequences.

We evaluated the number of alleles, $H_{O}$, and $H_{E}$ at singlelocus EST-SSR markers. Markers, TsuENH008 and TsuENH016 showed multiple fragments only in European pears, perhaps because they originated from multiple loci
(Table 1) and so were excluded from the data analysis of European pears. Likewise, marker TsuENH012 showed multiple fragments only in Japanese pears, and so was excluded from the data analysis of Japanese pears. EST-SSRs with di-nucleotide motifs showed two to six alleles in Japanese pears and one to eight in European pears (Table 3). EST-SSRs with tri-nucleotide motifs showed one to four alleles in Japanese pears and one to six in European pears, which is less than half, on average, of the number among di-nucleotide EST-SSRs. Values of $H_{O}$ and $H_{E}$ among trinucleotide EST-SSRs were one-third of those among dinucleotide EST-SSRs, indicating that di-nucleotide ESTSSRs generated much more heterozygosity than tri-nucleotide EST-SSRs.

\section{Mapping of EST-SSR markers}

Fifty-three SSR markers generated 57 loci which were identified in at least one linkage maps (Fig. 1). All 30 dinucleotide EST-SSRs were mapped, but only 20 out of 40 tri-nucleotide (or hexa-nucleotide) EST-SSRs were mapped. Two EST-SSRs with tetra-nucleotide motifs and one with penta-nucleotide motifs were mapped.

Out of the 53 EST-SSRs, 49 markers showing one segregating locus generated 49 mapped loci (Fig. 1). Four multiple-locus EST-SSRs had two segregating loci which were mapped in different linkage groups (Fig. 1): TsuENH004, LGs 4 and 12; TsuENH011, LGs 6 and 14; TsuENH042, LGs 13 and 16; and TsuENH054, LGs 13 and 16. The 57 EST-SSR loci were distributed across all 17 LGs.

\section{Transferability to related genera}

Out of 61 pear EST-SSRs, 51 (83\%) generated clear amplification in apple, comprising 21 di-nucleotide, 29 trinucleotide (or hexa-nucleotide), and one penta-nucleotide EST-SSRs showing transferability. But only $17(<28 \%)$ generated clear amplification in almond or peach, showing limited transferability across subfamilies. No distinct differences in transferability across genera were observed between di-nucleotide and tri-nucleotide EST-SSRs.

\section{Discussion}

Until now, few EST-SSR markers have been reported in pears. Here, we established 73 EST-SSR markers from 10,350 unigenes collected from the Japanese pear 'Housui'. Since fewer than 400 pear EST sequences were available in the public databases, we tested many candidates for developing EST-SSR and SNP markers. We identified the genome positions of many EST-SSR sequences showing significant homology to $A$. thaliana genes. These will be useful as functional markers that are transferable between different genetic backgrounds, and will be suitable for relatively highthroughput genotyping for MAS (Celton et al. 2009, Chagné et al. 2008, Newcomb et al. 2006). They will be also useful for genetic diversity studies and association genetics.

The EST-SSRs showed high polymorphism, identified as 


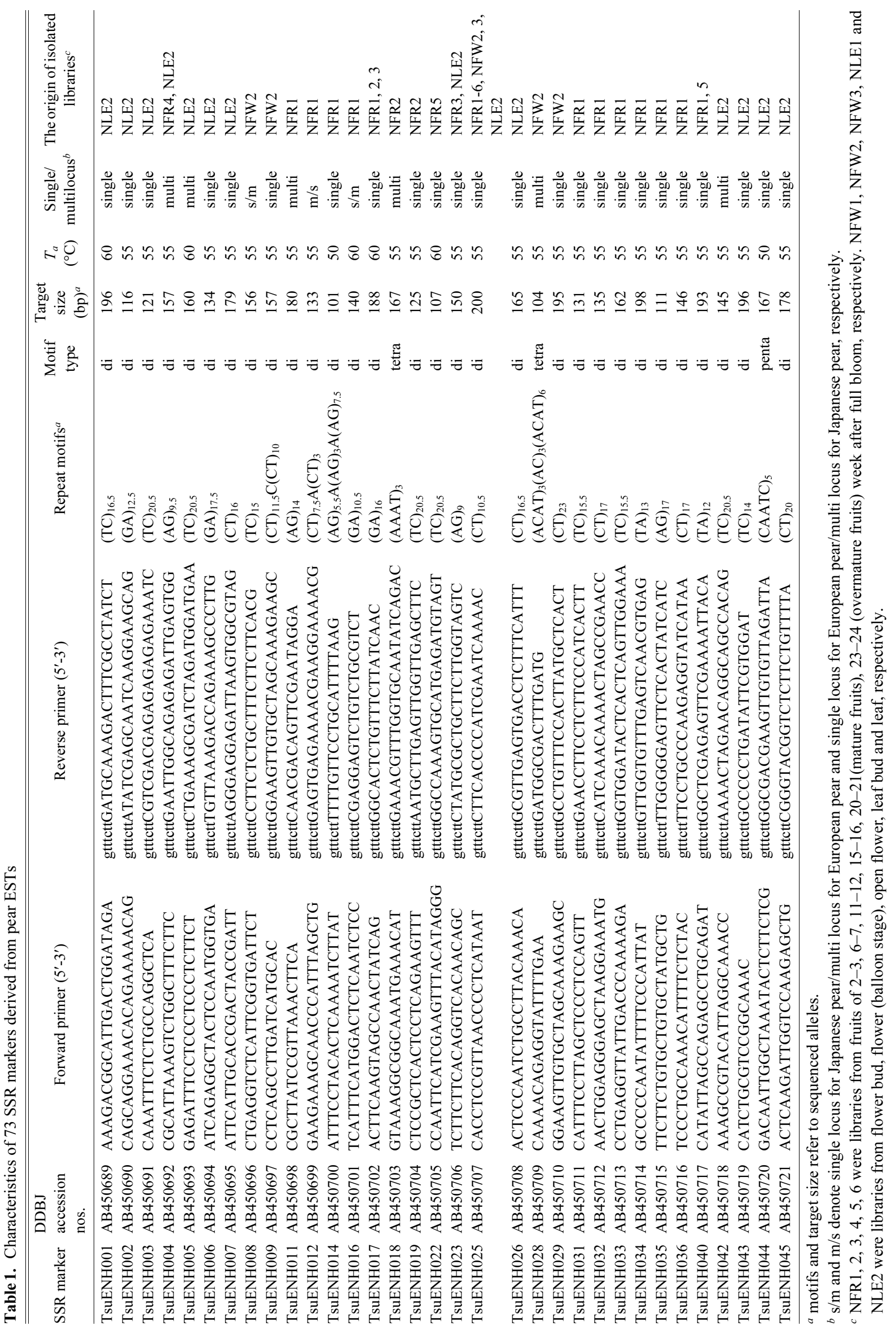




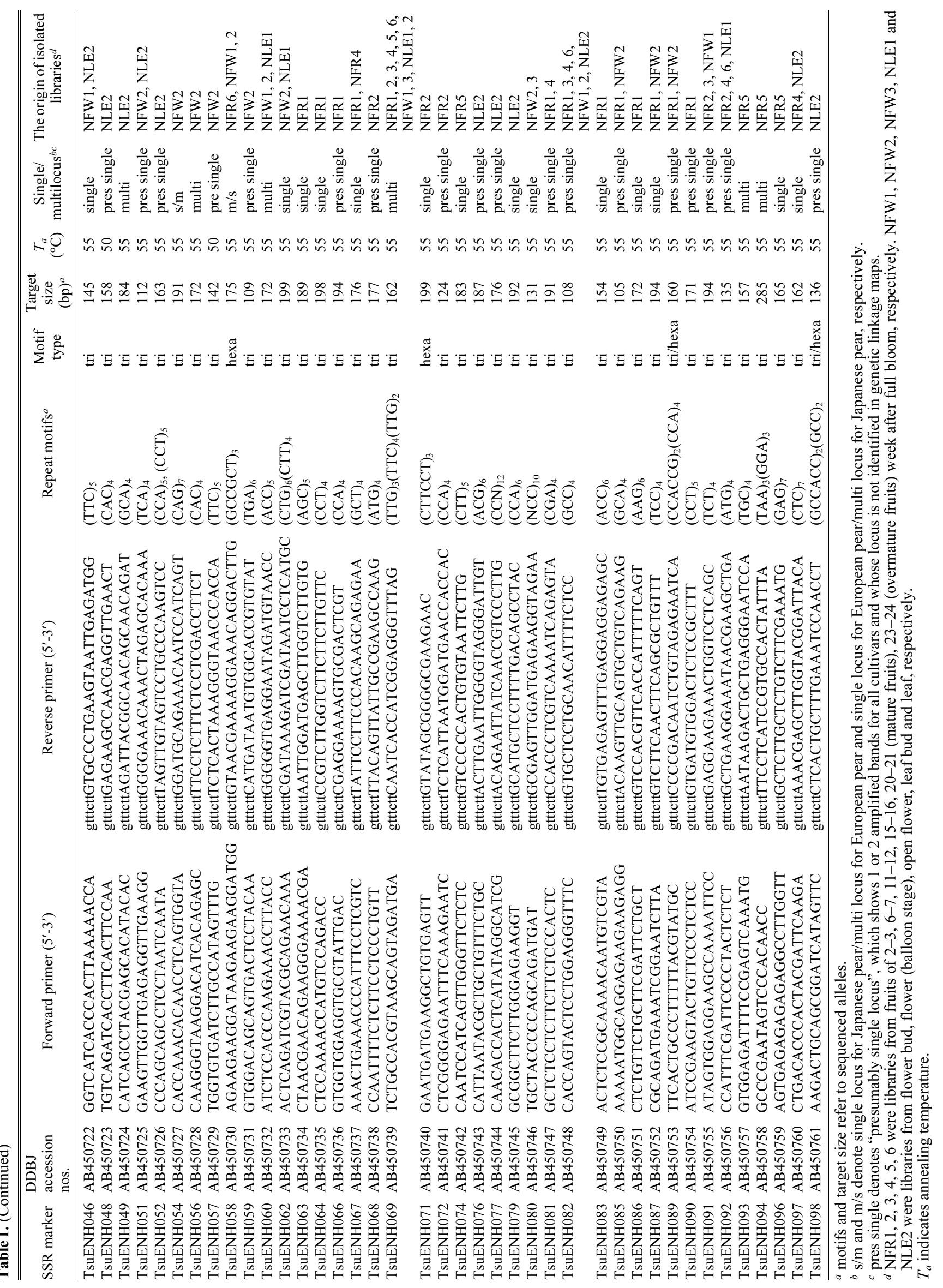


Table 2. SSR sequences showing significant homology to Arabidopsis thaliana genes

\begin{tabular}{|c|c|c|c|}
\hline SSR marker & Homologues of Arabidopsis gene name & ID nos. & E-value \\
\hline TsuENH001 & Ferredoxin-NADP $(+)$ reductase, putative & At5g66190 & $3 \mathrm{E}-37$ \\
\hline TsuENH002 & WRKY family transcription factor & Atlg13960 & $2 \mathrm{E}-14$ \\
\hline TsuENH003 & ADP-ribosylation factor, putative & At5g17060 & $6 \mathrm{E}-68$ \\
\hline TsuENH004 & Amino acid permease, putative (AUX1) & At2g38120 & $3 \mathrm{E}-21$ \\
\hline TsuENH008 & Smr (Small MutS Related) domain-containing & At2g26280 & $1 \mathrm{E}-11$ \\
\hline TsuENH011 & Expressed protein contains Pfam profile & At3g18215 & $6 \mathrm{E}-63$ \\
\hline TsuENH012 & Phosphoesterase family protein low & At3g48610 & $2 \mathrm{E}-82$ \\
\hline TsuENH014 & Phosphoglycerate/bisphosphoglycerate & At1g08940 & $3 \mathrm{E}-71$ \\
\hline TsuENH017 & Auxin-responsive AUX/IAA family protein & At4g29080 & $2 \mathrm{E}-31$ \\
\hline TsuENH019 & Tetratricopeptide repeat (TPR)-containing & At4g22670 & $1 \mathrm{E}-20$ \\
\hline TsuENH022 & Expressed protein & At3g03280 & 9E-09 \\
\hline TsuENH023 & TATA box-binding protein & At5g22330 & $7 \mathrm{E}-64$ \\
\hline TsuENH025 & S-adenosylmethionine synthetase 1 (SAM1) & At1g02500 & $7 \mathrm{E}-16$ \\
\hline TsuENH026 & Expansin, putative (EXP5) & At3g29030 & $7 \mathrm{E}-23$ \\
\hline TsuENH029 & Squamosa promoter-binding protein-like & At3g 15270 & $4 \mathrm{E}-31$ \\
\hline TsuENH031 & Dof-type zinc finger protein & At5g62940 & $1 \mathrm{E}-40$ \\
\hline TsuENH032 & Dof-type zinc finger protein & At5g62940 & $1 \mathrm{E}-40$ \\
\hline TsuENH033 & Developmental protein SEPALLATA1 / floral & At5g 15800 & $1 \mathrm{E}-46$ \\
\hline TsuENH034 & WRKY family transcription factor & At4g31550 & $7 \mathrm{E}-45$ \\
\hline TsuENH036 & $\mathrm{ABC}$ transporter family protein & At3g25620 & $3 \mathrm{E}-52$ \\
\hline TsuENH040 & Leucine-rich repeat transmembrane protein & At1g09970 & $1 \mathrm{E}-23$ \\
\hline TsuENH043 & Succinyl-CoA ligase & At2g20420 & $3 \mathrm{E}-72$ \\
\hline TsuENH044 & Ubiquitin-conjugating enzyme 20 (UBC20) & Atlg50490 & $8 \mathrm{E}-27$ \\
\hline TsuENH048 & 4-hydroxyphenylpyruvate dioxygenase (HPD) & Atlg06570 & $4 \mathrm{E}-30$ \\
\hline TsuENH049 & Expressed protein & At5g62090 & $5 \mathrm{E}-12$ \\
\hline TsuENH051 & $60 \mathrm{~S}$ ribosomal protein $\mathrm{L} 5$ similar to $60 \mathrm{~S}$ & At3g25520 & $2 \mathrm{E}-20$ \\
\hline TsuENH054 & NHL repeat-containing protein & Atlg70280 & $2 \mathrm{E}-33$ \\
\hline TsuENH056 & $60 \mathrm{~S}$ acidic ribosomal protein $\mathrm{P} 2$ (RPP2A) & At2g27720 & $4 \mathrm{E}-12$ \\
\hline TsuENH057 & Smr (Small MutS Related) & At2g26280 & $1 \mathrm{E}-11$ \\
\hline TsuENH063 & Expressed protein contains Pfam domain & At4g11860 & $2 \mathrm{E}-69$ \\
\hline TsuENH064 & Thioredoxin family protein & At3g16110 & $3 \mathrm{E}-29$ \\
\hline TsuENH067 & $60 \mathrm{~S}$ acidic ribosomal protein $\mathrm{P} 0$ (RPP0C) & At3g1 11250 & $2 \mathrm{E}-43$ \\
\hline TsuENH068 & GCIP-interacting family protein & At2g16860 & $8 \mathrm{E}-21$ \\
\hline TsuENH071 & Embryo-specific protein-related & At5g62200 & $3 \mathrm{E}-51$ \\
\hline TsuENH074 & Plastocyanin-like domain-containing & Atlg08500 & $5 \mathrm{E}-43$ \\
\hline TsuENH076 & DEAD/DEAH box helicase, putative (RH10) & At5g60990 & $1 \mathrm{E}-38$ \\
\hline TsuENH079 & Proline-rich extensin-like family protein & Atlg21310 & $8 \mathrm{E}-12$ \\
\hline TsuENH080 & $\mathrm{C} 2$ domain-containing protein & At3g16510 & $4 \mathrm{E}-11$ \\
\hline TsuENH081 & Thioredoxin family protein & At5g60640 & $8 \mathrm{E}-46$ \\
\hline TsuENH082 & Adenosylhomocysteinase, putative & At3g23810 & $3 \mathrm{E}-99$ \\
\hline TsuENH083 & DEAD/DEAH box helicase, putative & At2g47330 & $8 \mathrm{E}-11$ \\
\hline TsuENH085 & $40 \mathrm{~S}$ ribosomal protein S12 (RPS12C) & At2g32060 & $4 \mathrm{E}-48$ \\
\hline TsuENH087 & Cysteine protease inhibitor, putative & At3g12490 & $4 \mathrm{E}-63$ \\
\hline TsuENH090 & Expressed protein & At2g46000 & $1 \mathrm{E}-40$ \\
\hline TsuENH091 & Serine/threonine protein kinase, putative & At5g63650 & $6 \mathrm{E}-49$ \\
\hline TsuENH092 & High mobility group protein beta 2 & At1g20696 & $4 \mathrm{E}-30$ \\
\hline TsuENH096 & Heterotrimeric $\mathrm{G}$ protein gamma-subunit & At3g63420 & $9 \mathrm{E}-14$ \\
\hline TsuENH097 & Hydroxyacylglutathione hydrolase, putative & At1g53580 & $8 \mathrm{E}-61$ \\
\hline
\end{tabular}

high observed and expected heterozygosities. In our previous study, 13 pear genomic SSRs with di-nucleotide motifs showed $H_{O}=0.69$ and $H_{E}=0.71$ (Yamamoto et al. 2002a), values similar to those of the di-nucleotide EST-SSRs reported here. Inoue et al. (2007) reported that pear genomic SSRs with di-nucleotide motifs showed values of $H_{O}=0.54$ and $H_{E}=0.52$ among 17 Japanese pears. Fernandez-Fernandez et al. (2006) reported that genomic SSRs derived from Euro- pean pear gave high of $H_{O}=0.67$ and $H_{E}=0.83$ among 21 Pyrus accessions. These results suggest that EST-SSRs with di-nucleotide motifs have high heterozygosity, similar to genomic SSRs.

We found higher polymorphism among EST-SSRs with di-nucleotide repeat motifs than among those with trinucleotide repeats. Higher polymorphism was found among di- and tetra-nucleotide repeats than tri-nucleotide repeats in 
Table 3. Characteristics of EST-SSRs applied for Japanese and European pears and releted genera

\begin{tabular}{|c|c|c|c|c|c|c|c|c|c|}
\hline \multirow{2}{*}{ SSR marker } & \multirow{2}{*}{ Motif type } & \multicolumn{3}{|c|}{ Japanese pear } & \multicolumn{3}{|c|}{ European pear } & \multicolumn{2}{|c|}{ "Amplification in ${ }^{b}$} \\
\hline & & No. of alleles & $H_{E}^{a}$ & $H_{E}^{a}$ & No. of alleles & $H_{E}^{a}$ & $H_{E}^{a}$ & Malus & Prunus \\
\hline TsuENH001 & $\mathrm{di}$ & 4 & 0.68 & 0.70 & 5 & 0.64 & 0.50 & + & + \\
\hline TsuENH002 & $\mathrm{di}$ & 3 & 0.46 & 0.60 & 3 & 0.63 & 0.80 & + & + \\
\hline TsuENH003 & $\mathrm{di}$ & 3 & 0.51 & 0.50 & 6 & 0.79 & 1.00 & - & - \\
\hline TsuENH006 & $\mathrm{di}$ & 3 & 0.64 & 0.70 & 2 & 0.10 & 0.10 & + & - \\
\hline TsuENH007 & $\mathrm{di}$ & 5 & 0.59 & 0.70 & 1 & 0 & 0 & + & - \\
\hline TsuENH008 & $\mathrm{di}$ & 6 & 0.70 & 0.40 & (multi) & & & + & - \\
\hline TsuENH009 & $\mathrm{di}$ & 6 & 0.79 & 1.00 & 8 & 0.84 & 0.90 & - & - \\
\hline TsuENH012 & $\mathrm{di}$ & (multi) & & & 3 & 0.61 & 0.90 & + & - \\
\hline TsuENH014 & $\mathrm{di}$ & 2 & 0.42 & 0.60 & 3 & 0.46 & 0.60 & - & - \\
\hline TsuENH016 & $\mathrm{di}$ & 4 & 0.47 & 0.50 & (multi) & & & + & + \\
\hline TsuENH017 & $\mathrm{di}$ & 4 & 0.41 & 0.20 & 3 & 0.64 & 0.80 & + & - \\
\hline TsuENH019 & $\mathrm{di}$ & 3 & 0.58 & 0.70 & 4 & 0.73 & 0.90 & + & + \\
\hline TsuENH022 & $\mathrm{di}$ & 5 & 0.68 & 0.70 & 3 & 0.41 & 0.50 & + & - \\
\hline TsuENH023 & $\mathrm{di}$ & 3 & 0.52 & 0.40 & 4 & 0.53 & 0.70 & + & - \\
\hline TsuENH025 & $\mathrm{di}$ & 3 & 0.54 & 0.70 & 6 & 0.73 & 0.90 & + & + \\
\hline TsuENH026 & $\mathrm{di}$ & 6 & 0.78 & 0.70 & 7 & 0.83 & 1.00 & - & - \\
\hline TsuENH029 & $\mathrm{di}$ & 6 & 0.79 & 1.00 & 8 & 0.84 & 0.90 & - & - \\
\hline TsuENH031 & $\mathrm{di}$ & 4 & 0.68 & 0.60 & 7 & 0.82 & 0.80 & + & + \\
\hline TsuENH032 & $\mathrm{di}$ & 6 & 0.80 & 0.80 & 5 & 0.78 & 0.60 & + & + \\
\hline TsuENH033 & $\mathrm{di}$ & 5 & 0.79 & 0.90 & 6 & 0.80 & 0.90 & + & - \\
\hline TsuENH034 & $\mathrm{di}$ & 4 & 0.70 & 0.80 & 7 & 0.83 & 0.40 & + & - \\
\hline TsuENH035 & $\mathrm{di}$ & 5 & 0.53 & 0.60 & 6 & 0.75 & 1.00 & + & - \\
\hline TsuENH036 & $\mathrm{di}$ & 5 & 0.72 & 0.90 & 4 & 0.41 & 0.50 & + & - \\
\hline TsuENH040 & $\mathrm{di}$ & 4 & 0.68 & 0.90 & 4 & 0.63 & 1.00 & + & + \\
\hline TsuENH043 & $\mathrm{di}$ & 4 & 0.75 & 0.50 & 4 & 0.65 & 0.70 & + & + \\
\hline TsuENH045 & di & 5 & 0.71 & 0.70 & 4 & 0.71 & 0.40 & + & - \\
\hline (average) & & $(4.32)$ & $(0.63)$ & $(0.67)$ & $(4.71)$ & $(0.63)$ & $(0.70)$ & & \\
\hline TsuENH046 & tri & 2 & 0.18 & 0.20 & 4 & 0.62 & 0.60 & + & - \\
\hline TsuENH048 & tri & 3 & 0.49 & 0.50 & 1 & 0 & 0 & + & + \\
\hline TsuENH051 & tri & 2 & 0.10 & 0.10 & 1 & 0 & 0 & + & - \\
\hline TsuENH052 & tri & 2 & 0.42 & 0.40 & 3 & 0.51 & 0.30 & + & - \\
\hline TsuENH054 & tri & 3 & 0.27 & 0.30 & (multi) & & & + & - \\
\hline TsuENH057 & tri & 2 & 0.18 & 0.00 & (multi) & & & - & - \\
\hline TsuENH059 & tri & 1 & 0 & 0 & 1 & 0 & 0 & + & - \\
\hline TsuENH062 & tri & 2 & 0.50 & 0.70 & 5 & 0.68 & 0.90 & + & - \\
\hline TsuENH063 & tri & 2 & 0.50 & 0.70 & 2 & 0.10 & 0.10 & + & - \\
\hline TsuENH064 & tri & 2 & 0.50 & 1.00 & 5 & 0.68 & 1.00 & + & - \\
\hline TsuENH066 & tri & 2 & 0.26 & 0.30 & 1 & 0 & 0 & + & - \\
\hline TsuENH068 & tri & 2 & 0.10 & 0.10 & 2 & 0.38 & 0.50 & + & - \\
\hline TsuENH071 & tri & 1 & 0 & 0 & 1 & 0 & 0 & - & - \\
\hline TsuENH072 & tri & 1 & 0 & 0 & 1 & 0 & 0 & + & + \\
\hline TsuENH074 & tri & 4 & 0.68 & 0.90 & 1 & 0 & 0 & + & - \\
\hline TsuENH076 & tri & 3 & 0.64 & 1.00 & 4 & 0.65 & 0.70 & + & + \\
\hline TsuENH077 & tri & 1 & 0 & 0 & 2 & 0.32 & 0.40 & + & - \\
\hline TsuENH079 & tri & 2 & 0.18 & 0.20 & 2 & 0.10 & 0.10 & + & - \\
\hline TsuENH080 & tri & 3 & 0.27 & 0.20 & 3 & 0.34 & 0.40 & + & - \\
\hline TsuENH081 & tri & 1 & 0 & 0 & 1 & 0 & 0 & + & - \\
\hline TsuENH082 & tri & 1 & 0 & 0 & 1 & 0 & 0 & + & + \\
\hline TsuENH083 & tri & 3 & 0.59 & 0.60 & 3 & 0.61 & 0.50 & + & - \\
\hline TsuENH085 & tri & 1 & 0 & 0 & 1 & 0 & 0 & + & - \\
\hline TsuENH086 & tri & 3 & 0.58 & 0.80 & 4 & 0.62 & 0.40 & - & - \\
\hline TsuENH087 & tri & 3 & 0.40 & 0.40 & 1 & 0 & 0 & + & - \\
\hline TsuENH090 & tri & 2 & 0.10 & 0.10 & 2 & 0.10 & 0.10 & + & - \\
\hline TsuENH091 & tri & 1 & 0 & 0 & 1 & 0 & 0 & + & + \\
\hline TsuENH092 & tri & 1 & 0 & 0 & 1 & 0 & 0 & - & - \\
\hline TsuENH096 & tri & 1 & 0 & 0 & 3 & 0.67 & 0.90 & + & - \\
\hline TsuENH097 & tri & 1 & 0 & 0 & 3 & 0.54 & 0.50 & - & - \\
\hline TsuENH058 & hexa & (multi) & & & 2 & 0.10 & 0.10 & + & + \\
\hline TsuENH067 & hexa & 1 & 0 & 0 & 2 & 0.42 & 0.60 & + & + \\
\hline TsuENH089 & hexa & 2 & 0.10 & 0.10 & 6 & 0.55 & 0.40 & + & - \\
\hline TsuENH098 & hexa & 1 & 0 & 0 & 1 & 0 & 0 & + & - \\
\hline (average) & & (1.88) & $(0.21)$ & $(0.26)$ & $(2.22)$ & $(0.25)$ & $(0.27)$ & & \\
\hline TsuENH044 & penta & 4 & 0.58 & 0.70 & 3 & 0.54 & 0.70 & + & - \\
\hline
\end{tabular}

${ }^{a} H_{E}$ and $H_{O}$ denote expected and observed heterozygosities, respectively.

${ }^{b}$ Cross genus amplification in Malus and Prunus is denoted as follows; '+', good amplification; '-', no amplification. 

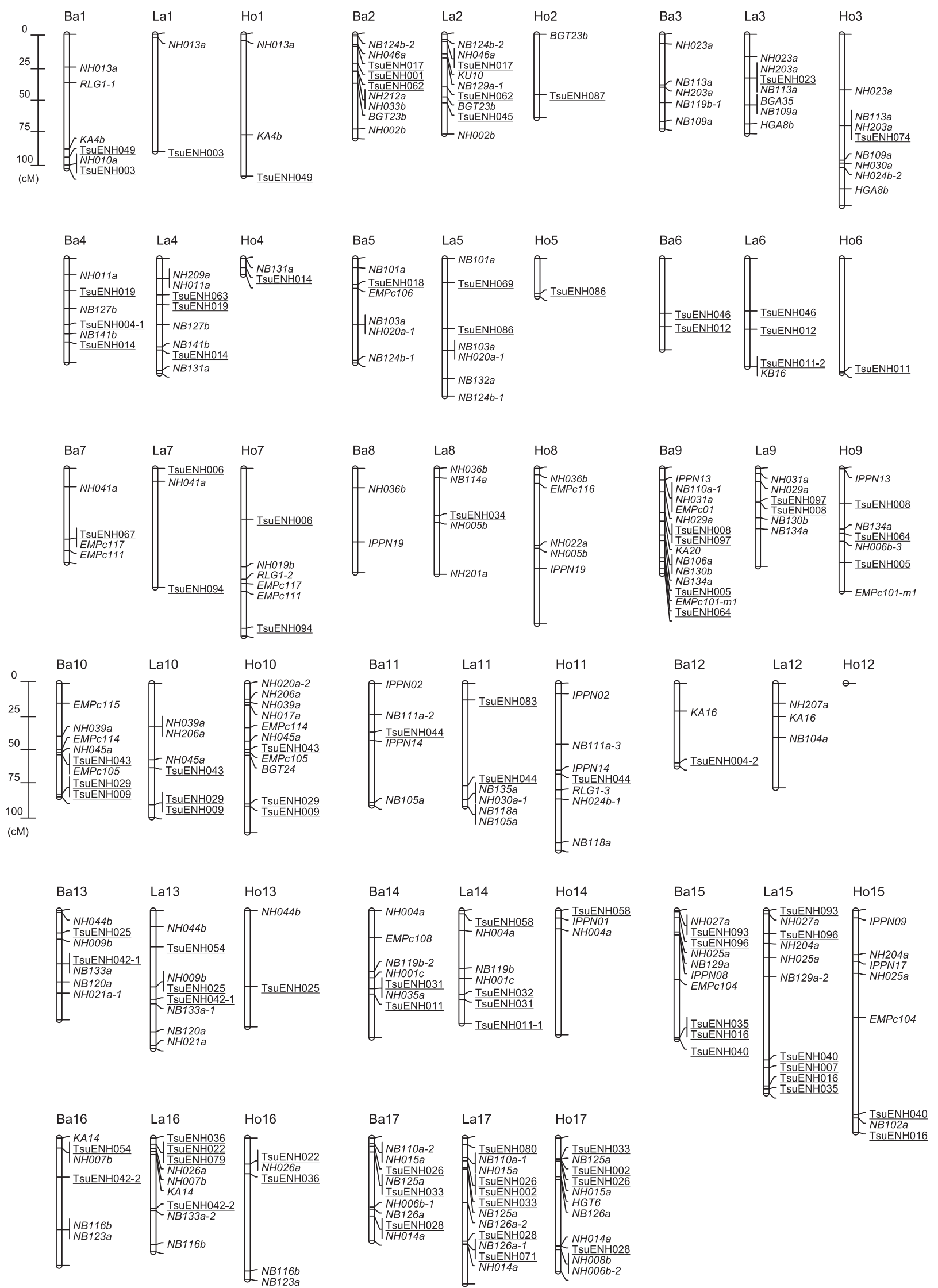

Fig. 1. Genetic linkage maps of 'Bartlett', 'La France', and 'Housui'. Linkage groups are designated Ba1-17 for 'Bartlett', La1-17 for 'La France' and Ho1-17 for 'Housui'. Pear EST-SSR loci are underlined; pear genomic SSR loci are italicized. 
apple (Celton et al. 2009), because di- and tetra-nucleotide repeats were usually found at higher frequency in $3^{\prime}$ and $5^{\prime}$ untranslated regions of genes, whereas tri-nucleotides were preferentially found in translated regions (Morgante et al. 2002). This uneven distribution of SSR motifs may be a result of mutation pressure and positive selection for specific single amino acid stretches. Yet although tri-nucleotide EST-SSRs may show low polymorphism, they can provide more precise allele identification, because tri-nucleotide SSRs generally give fewer "stutter bands" than di-nucleotide SSRs (Diwan and Cregan 1997).

Integrated reference genetic linkage maps based on SSR and AFLP markers have been constructed in pears (Yamamoto et al. 2004, 2007, Terakami et al. 2009). Here, the distribution of the 57 new EST-SSR loci across all 17 LGs, could improve pear reference genetic linkage maps: Although more than 100 pear genomic SSR loci have been mapped, genomic SSRs remain sparse in several regions. We found some EST-SSR loci in such sparse regions, including LG 6, the bottom of LG 1, and the bottom of LG 15 . In apple, $36 \%$ of EST-SSRs were mapped, a lower ratio than that of genomic SSRs, and some EST-SSRs could be mapped in regions where genomic SSRs are sparse, such as LG 1 (Celton et al. 2009).

More than $80 \%$ of the pear EST-SSR markers could be transferred from pear to apple, which belongs to the same subfamily (Maloideae). The transferability and positional conservation of SSR markers suggest a syntenic relationship between pear and apple (Yamamoto et al. 2004, 2007, Pierantoni et al. 2004, Celton et al. 2009). Our new pear ESTSSR markers pave the way for the development of markers for the same phenotypic traits between pear and apple.

Fewer than $30 \%$ of pear EST-SSR markers were transferable to almond and peach, in the subfamily Prunoideae. Liebhard et al. (2002) reported that among 15 (AG) $)_{\mathrm{n}}$ microsatellite markers developed in apple, only one amplified scorable bands in the Prunoideae. About half of $40(\mathrm{AG})_{\mathrm{n}}$ peach microsatellites gave amplification in both Prunus and either Malus or Fragaria (Dirlewanger et al. 2002). Nishitani et al. (2007) reported that $40 \%$ to $51 \%$ of peach trinucleotide SSR markers amplified fragments in Malus, Pyrus, Fragaria, and Rosa. Although the transferability of pear EST-SSRs to other subfamilies is not high, functional EST markers in pear will lead to the development of universal gene-specific markers in mapping and synteny studies within the Rosaceae.

\section{Acknowledgements}

Contribution No. 1536 of the National Institute of Fruit Tree Science. We are grateful to Drs. T. Imai, T. Saito, T. Kimura, and T. Hayashi for their valuable suggestions and useful discussion. This work was partially supported by a grant from the Ministry of Agriculture, Forestry and Fisheries of Japan (Genomics for Agricultural Innovation, DD-4040).

\section{Literature Cited}

Bell,R.L. (1990) Pears (Pyrus). In: Moore,J.N. and J.R.Ballington Jr. (eds.) Genetic Resources of Temperate Fruit and Nut Crops I. International Society for Horticultural Science, Wageningen, The Netherlands, pp. 655-697.

Bell,R.L., H.A.Quamme, R.E.C.Layne and R.M.Skirvin (1996) Pears. In: Janick,J. and J.N.Moore (eds.) Fruit Breeding, Volume I: Tree and Tropical Fruits. John Wiley \& Sons, Inc., pp. 441-514.

Benson, G. (1999) Tandem repeats finder, a program to analyze DNA sequence. Nucleic Acids Res. 27: 573-580.

Berardini,T.Z., S.Mundodi, R.Reiser, E.Huala, M.Garcia-Hernandez, P.Zhang, L.M.Mueller, J.Yoon, A.Doyle, G.Lander et al. (2004) Functional annotation of the Arabidopsis genome using controlled vocabularies. Plant Physiol. 135: 1-11.

Bonfield,J.K., K.F.Smith and R.Staden (1995) A new DNA sequence assembly program. Nucleic Acids Res. 24: 4992-4999.

Celton, J.M., D.S. Tustin, D.Chagné and S.E.Gardiner (2009) Construction of a dense genetic linkage map for apple rootstocks using SSRs developed from Malus ESTs and Pyrus genomic sequences. Tree Genet. Genomes 5: 93-107.

Chagné,D., K. Gasic, R.N.Crowhurst, Y.Han, H.C. Bassett, D.R. Bowatte, T.J.Lawrence, E.H.A.Rikkerink, S.E. Gardiner and S.S.Korban (2008) Development of a set of SNP markers present in expressed genes of the apple. Genomics 92: 353-358.

Decroocq, V., M.G.Favé, L.Hagen, L.Bordenave and S.Decroocq (2003) Development and transferability of apricot and grape EST microsatellite markers across taxa. Theor. Appl. Genet. 106: 912 922.

Dirlewanger,E., P.Cosson, M. Tavaud, M.J. Aranzana, C. Poizat, A.Zanetto, P.Arús and F.Laigret (2002) Development of microsatellite markers in peach [Prunus persica (L.) Batsch] and their use in genetic diversity analysis in peach and sweet cherry (Prunus avium L.). Theor. Appl. Genet. 105: 127-138.

Dirlewanger,E., E.Graziano, T.Joobeur, F.Garriga-Caldere, P.Cosson, W.Howad and P.Arús (2004) Comparative mapping and markerassisted selection in Rosaceae fruit crops. Proc. Natl. Acad. Sci. USA 101: 9891-9896.

Diwan, N. and P.B.Cregan (1997) Automated sizing of fluorescentlabeled simple sequence repeat (SSR) markers to assay genetic variation in soybean. Theor. Appl. Genet. 95: 723-733.

Dondini,L., L.Pierantoni, F.Gaiotti, R.Chiodini, S.Tartarini, C.Bazzi and S.Sansavini (2004) Identifying QTLs for fire-blight resistance via a European pear (Pyrus communis L.) genetic linkage map. Mol. Breed. 14: 407-418

Fernandez-Fernandez,F., N.G.Harvey and C.M.James (2006) Isolation and characterization of polymorphic microsatellite markers from European pear (Pyrus communis L.). Mol. Ecol. Notes 6: 10391041.

Gianfranceschi,L., N.Seglias, R.Tarchini, M.Komjanc and C.Gessler (1998) Simple sequence repeats for the genetic analysis of apple. Theor. Appl. Genet. 96: 1069-1076.

Grattapaglia,D. and R. Sederoff (1994) Genetic linkage maps of Eucalyptus grandis and Eucalyptus urophylla using a pseudotestcross: mapping strategy and RAPD markers. Genetics 137 : $1121-1137$.

Guilford,P., S.Prakash, J.M.Zhu, E.Rikkerink, S.Gardiner, H.Bassett and R.Forster (1997) Microsatellites in Malus $\times$ domestica (apple): abundance, polymorphism and cultivar identification. Theor. Appl. Genet. 94: 249-254.

Howad, W., T. Yamamoto, E. Dirlewanger, R. Testolin, P.Cosson, 
G.Cipriani, A.J.Monforte, L.Georgi, A.G. Abbot and P. Arús (2005) Mapping with a few plants: using selective mapping for microsatellite saturation of the Prunus reference map. Genetics 171: 1305-1309.

Inoue,E., Y.Matsuki, H.Anzai and K.Evans (2007) Isolation and characterization of microsatellite markers in Japanese pear (Pyrus pyrifolia Nakai). Mol. Ecol. Notes 7: 445-447.

Kikuchi,A. (1929) Investigations in 1927 and 1928. 1. Paterclinical incompatibility in the Japanese pear. J. Okitsu Hort. Soc. 24: 1-6.

Liebhard, R., L.Gianfranceschi， B. Koller，C.D. Ryder，R. Tarchini, E.Vande Weg and C.Gessler (2002) Development and characterisation of 140 new microsatellites in apple (Malus $\times$ domestica Borkh.). Mol. Breed. 10: 217-241.

Marshall,T.C., J.Slate, L.Kruuk and J.M.Pemberton (1998) Statistical confidence for likelihood-based paternity inference in natural populations. Mol. Ecol. 7: 639-655.

Morgante,M., M.Hanafey and W.Powell (2002) Microsatellites are preferentially associated with non repetitive DNA in plant genomes. Nat. Genet. 30: 194-200.

Naik, S., C.Hampson, K.Gasic, G.Bakkeren and S.S.Korban (2006) Development and linkage mapping of E-STS and RGA markers for functional gene homologs in apple. Genome 49: 959-968.

Newcomb, R.D., R.N. Crowhurst, A.P. Gleave, E.H.A. Rikkerink, A.C.Allan, L.L. Beuning, J.H.Bowen， E. Gera， K.R. Jamieson, B.J.Janssen et al. (2006) Analyses of expressed sequence tags from apple. Plant Physiol. 141: 147-166.

Nishitani,C., T.Kimura, E.Ueda, W.Howad, P.Arús and T.Yamamoto (2007) Tri-/Hexanucleotide microsatellite markers in peach derived from enriched genomic libraries and their application in Rosaceae. Breed. Sci. 57: 289-296.

Nishitani, C., T. Shimizu, H.Fujii, S. Terakami and T. Yamamoto (2009) Analysis of expressed sequence tags from Japanese pear 'Housui'. Acta Hort. 814: 645-649.

Pierantoni,L., K.H.Cho, I.S.Shin, R.Chiodini, S.Tartarini, L.Dondini, S.J.Kang and S.Sansavini (2004) Characterisation and transferability of apple SSRs to two European pear F1 populations. Theor. Appl. Genet. 109: 1519-1524.

Rozen,S. and H.J.Skaletsky (2000) Primer3 on the WWW for general users and for biologist programmers. In: Krawetz,S. and S.Misener (eds.) Bioinformatics Methods and Protocols: Methods in Molecular Biology. Humana Press, Totowa N.J., pp.365-386.

Sawamura, Y., T.Saito, N.Takada, T.Yamamoto, T.Kimura, T.Hayashi and K.Kotobuki (2004) Identification of parentage of Japanese pear 'Housui'. J. Japan. Soc. Hort. Sci. 73: 511-518.

Silfverberg-Dilworth,E., C.L.Matasci, W.E.Van de Weg, M.P.W.Van Kaauwen, M. Walser, L.P. Kodde, V.Soglio, L. Gianfranceschi, C.E.Durel, F.Costa et al. (2006) Microsatellite markers spanning the apple (Malus $\times$ domestica Borkh.) genome. Tree Genet. Genomes 2: 202-224.

Terakami, S., T.Kimura, C. Nishitani, Y.Sawamura, T. Saito, T. Hirabayashi and T.Yamamoto (2009) Genetic linkage map of the Japanese pear 'Housui' identifying three homozygous genomic regions. J. Jpn. Soc. Hort. Sci. 78 (in press)

Van Ooijen,J.W. and R.E.Voorrips (2001) JoinMap 3.0: Software for the calculation of genetic linkage maps. Plant Research International, Wageningen.

Wan,C.Y. and T.A.Wilkins (1994) A modified hot borate method significantly enhances the yield of high-quality RNA from cotton (Gossypium hirsutum L.). Analytical Biochemistry 223: 7-12.

Weber,J.K. and P.E.May (1989) Abundant class of human DNA polymorphisms which can be typed using the polymerase chain reaction. Am. J. Hum. Genet. 44: 388-397.

Yamamoto, T., T.Kimura, Y.Sawamura, K.Kotobuki, Y.Ban, T. Hayashi and N.Matsuta (2001) SSRs isolated from apple can identify polymorphism and genetic diversity in pear. Theor. Appl. Genet. 102: 865-870.

Yamamoto,T., T.Kimura, M.Shoda, Y.Ban, T.Hayashi and N.Matsuta (2002a) Development of microsatellite markers in Japanese pear (Pyrus pyrifolia Nakai). Mol. Ecol. Notes 2: 14-16.

Yamamoto, T., T.Kimura, Y.Sawamura, T.Manabe, K. Kotobuki, T.Hayashi, Y.Ban and N.Matsuta (2002b) Simple sequence repeats for genetic analysis in pear. Euphytica 124: 129-137.

Yamamoto,T., T.Kimura, M.Shoda, T.Imai, T.Saito, Y.Sawamura, K.Kotobuki, T.Hayashi and N.Matsuta (2002c) Genetic linkage maps constructed by using an interspecific cross between Japanese and European pears. Theor. Appl. Genet. 106: 9-18.

Yamamoto, T., T. Kimura, T. Saito, K. Kotobuki， N. Matsuta， R. Liebhard, C.Gessler, W.E.van de Weg and T.Hayashi (2004) Genetic linkage maps of Japanese and European pears aligned to the apple consensus map. Acta Hort. 663: 51-56.

Yamamoto,T., T.Kimura, T.Hayashi and Y.Ban (2006) DNA profiling of fresh and processed fruits in pear. Breed. Sci. 56: 165-171.

Yamamoto,T., T.Kimura, S.Terakami, C.Nishitani, Y.Sawamura, T.Saito, K.Kotobuki and T.Hayashi (2007) Integrated reference genetic linkage maps of pear based on SSR and AFLP markers. Breed. Sci. 57: 321-329. 